\title{
Effectiveness of Nerve Blocks for the Management of Head and Neck Cancer Associated Neuropathic Pain Disorders; a Retrospective Study
}

\author{
Khawaja Shehryar Nasir' ${ }^{1}$, Haroon Hafeez ${ }^{1}$, Arif Jamshed ${ }^{2}$, Raza T. Hussain ${ }^{3}$ \\ 'Department of Internal Medicine, Shaukat Khanum Memorial Cancer Hospital and Research Centre, \\ Lahore, Pakistan, ${ }^{2}$ Department of Clinical and Radiation Oncology, Shaukat Khanum Memorial Cancer \\ Hospital and Research Centre, Lahore, Pakistan, ${ }^{3}$ Department of Surgical Oncology, Shaukat Khanum \\ Memorial Cancer Hospital and Research Centre, Lahore, Pakistan
}

Received: 15 April 2020/Accepted: 20 May 2020

\section{Open ACCESS}

Correspondence: Khawaja Shehryar Nasir, 7-A Block R-3, Phase 2, M.A. Johar Town, Lahore, Punjab 54782, Pakistan. Email: shehryarnasir@skm.org.pk

Citation: Nasir KS, Hafeez $\mathrm{H}$, Jamshed A, Hussain R Effectiveness of nerve blocks for the management of head and neck cancer associated neuropathic pain disorders; a retrospective study. J Cancer Allied Spec [Internet]. 2020May12; 6(2):e1002957. https://doi.org/10.37029/jcas. v6i2.367

Copyright: (c) 2020 Nasir, et al. This is an open access article distributed under the terms of the Creative Commons Attribution License, which permits unrestricted use, distribution, and reproduction in any medium, provided the original author and source are credited.

Funding: Nil.

Competing interests: Nil.

\begin{abstract}
Introduction: A portion of patients with head and neck cancer (HNC)associated pain may not experience relief in symptoms with non-invasive modalities. A nerve block is a procedure in which a local anaesthetic agent is injected along the nerve track to preferentially block sensory transmission. The literature on the effectiveness of nerve blocks in the management of HNC-related pain is limited. The purpose of this study was to determine the effectiveness of nerve blocks in the management of breakthrough HNC-associated trigeminal or cervical neuropathic pain disorders. Materials and Methods: A retrospective chart review of patients who underwent a nerve block or infiltration procedure in the regions of head and neck for the management of breakthrough HNC-associated trigeminal or cervical neuropathic pain disorders in the Orofacial Pain Medicine Clinic, Shaukat Khanum Memorial Cancer Hospital and Research Centre, between November 2018 and November 2019 was completed. Information regarding demographics, diagnosis and pain characteristics was extracted and reviewed. The Fisher's exact test and Mann-Whitney U-test were used for analysis between independent and dependent variables. Results: A total of 27 participants were included in the investigation, of which $66.7 \%$ were male. The average pre-procedure pain score was $6.85 \pm 2.54$. Following intervention, $81.5 \%$ of the participants experienced $>75 \%$ relief in pain for longer than 48 hours. The mean immediate post-procedure pain score was $0.26 \pm 1.02$ and the average duration of relief was $6.10 \pm 6.50$ weeks. The significant effect of nerve blocks was found to be statistically associated with the concurrent use of amitriptyline $(P=0.017)$. Conclusion: Nerve blocks, as an adjunctive therapy to pharmacologic treatment, can provide significant relief to patients with breakthrough $\mathrm{HNC}$-associated trigeminal and cervical neuropathic pain disorders. However, the duration of relief experienced by the participants is inconsistent. The beneficial effect of nerve blocks appears to be more common in patients that were concurrently using amitriptyline.
\end{abstract}

Key words: Cancer, nerve blocks, neuropathic pain, pain management, trigeminal 


\section{Introduction}

Pain is a common symptom associated with cancer and its treatment. The overall prevalence of cancer-related pain ranges from $40 \%$ to $60 \%$. Among various cancer types, the prevalence of pain in head and neck cancers (HNCs) is the highest, with estimates up to $86 \% .^{[1]}$ This is likely due to the erosive and aggressive nature of the disease process as well as the extensive and rich nerve supply of the craniofacial region. Similarly, complex functional and parafunctional jaw and cervical movements may cause dynamic pain. ${ }^{[2,3]}$

The management of cancer-related pain primarily consists of disease-modifying treatments (surgery, radiation therapy and chemotherapy) and pharmacotherapy. Other options include nonpharmacological interventions, such as physical and occupational therapy and behavioural pain management. Altogether, these modalities can help in improving pain control and reducing painassociated disability and distress. ${ }^{[4,5]}$ Nonetheless, in $10-20 \%$ of HNC-related pain cases, pain may become refractory and not resolve with conventional measures. ${ }^{[6]}$ Such patients may find relief from interventional modalities, such as peripheral nerve infiltration or blocks or neurolysis procedures. $^{[4,6,7]}$

A nerve infiltration or block is a procedure in which a local anaesthetic agent is injected along the nerve track to preferentially block sensory nerves. Local anaesthetics reversibly inhibit voltage-gated sodium channels, thereby impairing conduction through sensory nerve fibres. ${ }^{[8-10]}$ The extent and duration of the block depend on various factors, such as the dose and pharmacokinetic properties of the anaesthetic, the characteristics of the nerve being anaesthetised such as thickness and myelination and the physiological and anatomical properties of the site of injection. ${ }^{[8,9]}$

Nerve blocks have previously been shown to be helpful in the management of refractory or breakthrough episodes of pain for various headache disorders and neuropathic pain conditions. ${ }^{[6,10-15]}$
However, there are a limited number of studies on the effectiveness of nerve blocks in the management of HNC-related pain. The aim of this study was to determine the effectiveness of nerve blocks in the management of breakthrough HNCassociated trigeminal or cervical neuropathic pain disorders.

\section{Materials and Methods}

\section{Participants, study design and clinical setting}

A retrospective chart review of patients who underwent a nerve block or infiltration procedure in the regions of the head and neck for the management of breakthrough HNC-associated trigeminal or cervical neuropathic pain disorders in the Orofacial Pain Medicine Clinic, Shaukat Khanum Memorial Cancer Hospital and Research Centre, between November 2018 and November 2019 was performed. Approval from the Institutional Research Ethics Committee was obtained (EX-23-12-19-01).

The diagnosis of HNC-associated trigeminal or cervical neuropathic pain was based on the International Headache Society diagnostic criteria for headache attributed to intracranial neoplasm and the International Classification of Orofacial Pain diagnostic criteria for trigeminal neuropathic pain attributed to other disorders ${ }^{[16,17]}[$ Table 1].

Before treatment with a nerve block, all participants received at least three concurrent classes of medications, consisting of an opioid analgesic, either a tricyclic antidepressant or gabapentinoids (gabapentin or pregabalin) and either paracetamol or non-steroidal anti-inflammatory medication for the management of HNC-associated pain, as per ESMO clinical practice guidelines. ${ }^{[18]}$ Participants were considered to have breakthrough pain if the use of these medications failed to alleviate the baseline pain of the patient by $50 \%$ for the entire intended duration between two consecutive doses of medications.

All adult male and female patients who had undergone a nerve block procedure in the 
Table 1: Diagnostic criteria for HNC-associated trigeminal or cervical neuropathic pain disorder, based on the ICOP criteria for trigeminal neuropathic pain attributed to other disorders, and ICHD-3 criteria for headache attributed to intracranial neoplasm

\footnotetext{
A. Pain, in neuroanatomically plausible area within the distribution(s) of one or both trigeminal or cervical nerve(s), persisting or recurring for $>3$ months and fulfilling criteria C and D

B. Neoplasm of the head-and-neck area has been identified

C. Evidence of causation demonstrated by one or more of the following:

1. Pain has developed in temporal relation to the HNC or led to its discovery

2. Pain has significantly worsened in parallel with worsening of the HNC

D. Pain is associated with somatosensory symptoms and/ or signs* in the same neuroanatomically plausible distribution

E. Not better accounted for by another ICOP or ICHD-3 diagnosis

*Somatosensory symptoms or signs may be negative (e.g., hypaesthesia and/or hypoalgesia) and/or positive (e.g., hyperalgesia and/or allodynia). HNC: Head-and-neck cancer, ICOP: International Classification of Orofacial Pain Disorders, ICHD-3: International Classification of Headache Disorders-3
}

head and neck region for the management of breakthrough $\mathrm{HNC}$-associated neuropathic pain were included in the investigation. HNCs were defined as carcinoma involving oral, oropharyngeal and nasopharyngeal regions, salivary glands, nasal cavity and paranasal sinus region and laryngeal and hypopharyngeal area. Excluded patients were those who underwent a chemical neurolysis procedure before the termination of anaesthetic or therapeutic response of the nerve blocks and patients that had nerve blocks for non-cancer or non-neuropathic pain disorders.

\section{Clinical information}

Medical charts were reviewed to collect data regarding patient demographics, cancer type and stage, primary site of disease, occurrence of metastasis, prior anti-cancer therapies (surgery, radiation therapy and chemotherapy), concurrent anti-cancer therapies (radiation therapy and chemotherapy) and medical history. The concurrent use of analgesics and adjuvant medications (muscle relaxants, antidepressants or neuropathic medications), irrespective of indication of use, was documented. Data regarding the pain score before and immediately after the administration of injections and at each patient encounter were noted. Patients rated their pain score on an 11-point Likert-type numeric verbal pain rating scale, in which 0 was indicative of no pain and 10 indicated their worst pain experience ever. Furthermore, information regarding the characteristics of pain (e.g., location, laterality, chronicity, frequency, quality and modifying factors) was documented. Information regarding the nerve(s) blocked and the type of anaesthetic agent used was noted.

\section{Protocol of nerve blocks}

Participants underwent a nerve block of at least one of the following nerves: Auriculotemporal nerve, mental nerve, inferior alveolar nerve, sphenopalatine ganglion, infraorbital nerve, superior alveolar nerves, supraorbital nerve, greater auricular nerve, greater and lesser occipital nerve and superficial cervical nerve plexus (C2-C4). The landmark technique was used for the administration of injections. ${ }^{[7,9]}$ Inferior alveolar nerve, mental nerve and infraorbital nerve injections were performed using an intraoral approach. Conversely, for rest of the injections, an extraoral approach was used. Patients received either lidocaine $2 \%$ with epinephrine $(1: 100,000)$ or bupivacaine $0.5 \%$ without epinephrine. The choice of anaesthetic agent was based on the availability of instruments and the anaesthetic agent. The site and the severity of the patient's pain directed the location, type and number of nerve blocks.

\section{Response to nerve blocks}

The response of participants to nerve blocks was considered to be significant, if the intervention resulted in at least $75 \%$ or more reduction in preprocedure pain, for at least 48 hours. The half-life of lignocaine $2 \%$ (with epinephrine) is estimated to be 
around 1.5-2 hours and the half-life of bupivacaine $0.5 \%$ (without epinephrine) is approximately 3.5 hours. A benchmark of 48 hours was utilised as it allows the anaesthetic effects of either of the two local anaesthetic agents to have resolved by this time period, and the analgesic response of the blocks would be evidently appreciable. The duration of relief in pain was reported in terms of number of weeks. This information was extracted from the subsequent visits of the patients to the Orofacial Pain Medicine Clinic. Participants who did not report for a follow-up visit after the injection therapy were considered to have no or minimal relief in symptoms for the purpose of the analysis.

\section{Statistical analysis}

The statistical analysis was performed using SPSS software (version 22.0; SPSS, Chicago, IL). Descriptive statistics were computed for each variable. If any study variable was missing for the included participants, it was excluded in the statistical analysis. The Fisher's exact test and MannWhitney U-test were used for analysis between independent and dependent variables. $P<0.05$ was considered as statistically significant.

\section{Results}

A total of 84 charts were identified and reviewed. Twenty-seven participants who underwent at least one nerve block for the management of breakthrough pain related to HNC-associated trigeminal or cervical neuropathic pain disorder were included in this investigation. Fifty-seven participants were excluded for either undergoing neurolysis procedure immediately after the nerve block or because they had nerve block for the management of non-cancerous or non-neuropathic pain disorder. Among the participants included, a total of 43 nerves were blocked. For the 27 participants included in the analysis, there were no missing data.

Patient characteristics are reviewed in Table 2. Of the 27 participants, 18 (66.7\%) were male. The average age of the cohort was $44.44 \pm 12.97$ years.
Table 2: Summary of demographic and diagnostic characteristics of the study population

\begin{tabular}{|c|c|c|}
\hline $\begin{array}{l}\text { Study } \\
\text { characteristic }\end{array}$ & Category & $\begin{array}{c}\text { Descriptive } \\
\text { statistic }\end{array}$ \\
\hline Age (years) & Mean & $44.44 \pm 12.97$ \\
\hline Gender & Male & $66.7 \%(18)$ \\
\hline Cancer type & $\begin{array}{l}\text { Squamous cell } \\
\text { carcinoma }\end{array}$ & $85.2 \%(23)$ \\
\hline Metastasis & & $59.3 \%(16)$ \\
\hline $\begin{array}{l}\text { Prior surgical inter- } \\
\text { vention }\end{array}$ & & $48.1 \%(13)$ \\
\hline Prior radiotherapy & & $88.9 \%(24)$ \\
\hline $\begin{array}{l}\text { Prior chemother- } \\
\text { apy }\end{array}$ & & $88.9 \%(24)$ \\
\hline $\begin{array}{l}\text { Concurrent radio- } \\
\text { therapy }\end{array}$ & & $7.4 \%(2)$ \\
\hline $\begin{array}{l}\text { Concurrent chemo- } \\
\text { therapy }\end{array}$ & & $51.9 \%(14)$ \\
\hline \multirow{5}{*}{$\begin{array}{l}\text { Primary tumour } \\
\text { site }\end{array}$} & Alveolar mucosa & $40.7 \%(11)$ \\
\hline & Tongue & $18.5 \%(5)$ \\
\hline & Buccal mucosa & $14.8 \%(4)$ \\
\hline & Parotid gland & $14.8 \%(4)$ \\
\hline & $\begin{array}{l}\text { Other (nasopha- } \\
\text { ryngeal, external } \\
\text { auditory canal and } \\
\text { hard palate) }\end{array}$ & $22.2 \%(6)$ \\
\hline
\end{tabular}

Nearly $85 \%$ of the participants had squamous cell carcinoma, with the primary tumour site most commonly being the alveolar mucosa of the maxillary or mandibular region (40.7\%). All of the participants had Stage IV disease, and in approximately $60 \%$ of the participants, there was evidence of disease metastasis. Almost half of the participants had undergone surgical intervention for the management of cancer, and nearly $89 \%$ of the participants had a history of undergoing radiation therapy and chemotherapy. At the time of intervention, nearly half of the participants were actively undergoing chemotherapy. The most common medical comorbidity was hypertension $(14.8 \%)$ and ischaemic heart disease (11.1\%).

The average pre-procedure pain score was $6.85 \pm 2.54$. In $81.5 \%$ of the participants, pain originated from the tumour alone, whereas the remaining $18.5 \%$ had pain originating secondary 
Original Article

to the tumour and as a toxicity of their cancer treatment. The pain was unilateral in almost $70 \%$ of the participants, and the most common sites of pain were along the distribution of mandibular division of trigeminal nerve (63\%) and cervical nerves (C2-C4) (59.3\%). Furthermore, nearly $40 \%$ of the participants had pain along at least two or more divisions. The most common descriptors of pain reported by the participants were burning (59.3\%), dull ache (59.3\%) and stabbing (59.3\%) [Table 3].

At the time of intervention, participants were concurrently using paracetamol (88.9\%), nonsteroidal anti-inflammatory drugs (63\%), tricyclic antidepressants (70.4\%), muscle relaxants (44.4\%), gabapentinoids (74.1\%) and opioids (100\%).

After undergoing the nerve block procedure, $81.5 \%$ of the participants had more than $75 \%$ relief in pain for longer than 48 hours. The mean immediate post-procedure pain score was $0.26 \pm 1.02$. The average duration of relief that was experienced by the participants following intervention was $6.10 \pm 6.50$ weeks. Among these, $74 \%$ of the participants had relief for 1 week or more, and almost $59 \%$ of the participants had relief for 1 month or more [Table 4]. The most anaesthetised nerves were the inferior alveolar nerve $(40.7 \%)$, superior cervical plexus (37\%) and auriculotemporal nerve (29.6\%).

The beneficial effect of nerve blocks was found to be statistically associated with the concurrent use of amitriptyline $(P=0.017)$. There was no statistical association present between any of the demographic and diagnostic variables, pain characteristics, medical comorbidities or other concurrent medications with the relief experienced by the participants following nerve block. These results are summarised in Tables 5 and 6 .

\section{Discussion}

The purpose of this study was to evaluate the effectiveness of nerve blocks in the management of breakthrough HNC-associated trigeminal or
Table 3: Summary of pain characteristics of the study population before intervention

\begin{tabular}{l|l|c}
\hline $\begin{array}{l}\text { Study } \\
\text { characteristic }\end{array}$ & Category & $\begin{array}{c}\text { Descriptive } \\
\text { statistic }\end{array}$ \\
\hline Pain score & Pre-procedure & $6.85 \pm 2.54$ \\
\hline Origin of pain & Tumour related & $81.5 \%(22)$ \\
\cline { 2 - 3 } & $\begin{array}{l}\text { Tumour and treatment } \\
\text { related }\end{array}$ & $18.5 \%(5)$ \\
\hline Pain laterality & Unilateral & $70.4 \%(19)$ \\
\hline \multirow{2}{*}{$\begin{array}{l}\text { Distribution of } \\
\text { pain }\end{array}$} & Ophthalmic division & $3.7 \%(1)$ \\
\cline { 2 - 3 } & Maxillary division & $18.5 \%(5)$ \\
\cline { 2 - 3 } & Mandibular division & $63.0 \%(17)$ \\
\cline { 2 - 3 } & Cervical nerve (C2-4) & $59.3 \%(16)$ \\
& distribution & $59.3 \%(16)$ \\
\hline \multirow{4}{*}{ Quality of pain } & Burning & $59.3 \%(16)$ \\
\cline { 2 - 3 } & Dull ache & $59.3 \%(16)$ \\
\cline { 2 - 3 } & Stabbing & $22.2 \%(6)$ \\
\cline { 2 - 3 } & Throbbing & $22.2 \%(6)$ \\
\cline { 2 - 3 } & Sharp & $14.8 \%(4)$ \\
\cline { 2 - 3 } & Other (electric, shooting) &
\end{tabular}

Table 4: Summary of the outcome of nerve blocks

\begin{tabular}{l|l|c}
\hline $\begin{array}{l}\text { Study } \\
\text { characteristic }\end{array}$ & Category & $\begin{array}{c}\text { Descriptive } \\
\text { statistic }\end{array}$ \\
\hline Pain score & $\begin{array}{l}\text { Immediately post-pro- } \\
\text { cedure }\end{array}$ & $0.26 \pm 1.02$ \\
\hline \multirow{2}{*}{$\begin{array}{l}\text { Relief in } \\
\text { symptoms }\end{array}$} & More than 48 hours & $81.5 \%(22)$ \\
\cline { 2 - 3 } & 1 week or more & $74.1 \%(20)$ \\
\cline { 2 - 3 } & 1 month or more & $59.3 \%(16)$ \\
\hline $\begin{array}{l}\text { Duration of } \\
\text { relief }\end{array}$ & Weeks & $6.10 \pm 6.50$ \\
\hline
\end{tabular}

cervical neuropathic pain disorders. Among the 27 participants enrolled in this retrospective study, $81.5 \%$ had $75 \%$ or more relief in symptoms for at least 48 hours, which on average lasted for 6.1 weeks. A statistically significant association was found between the effectiveness of nerve blocks and concurrent use of amitriptyline.

Regional nerve blocks have been shown to be effective in the management of pain associated with migraine and cluster headache disorders, trigeminal and occipital neuralgias, trigeminal neuropathic pain disorders and neuropathic 
Table 5: Breakdown of demographic and diagnostic characteristics of the study population based on response to nerve blocks

\begin{tabular}{|c|c|c|c|c|}
\hline \multirow[t]{2}{*}{ Study characteristic } & \multirow[t]{2}{*}{ Category } & \multicolumn{2}{|c|}{ Significant improvement } & \multirow[t]{2}{*}{$P$-value } \\
\hline & & Yes & No & \\
\hline Age (years) & Mean & $43.23 \pm 13.08$ & $49.80 \pm 12.30$ & 0.34 \\
\hline Gender & Male & $88.9 \%(16)$ & $11.1 \%(2)$ & 0.30 \\
\hline Cancer type & Squamous cell carcinoma & $82.6 \%(19)$ & $17.4 \%(4)$ & 1.00 \\
\hline Metastasis & & $87.5 \%(14)$ & $12.5 \%(2)$ & 0.37 \\
\hline Prior surgical intervention & & $84.6 \%(11)$ & $15.4 \%(2)$ & 1.00 \\
\hline Prior radiotherapy & & $87.5 \%(21)$ & $12.5 \%(3)$ & 0.08 \\
\hline Prior chemotherapy & & $87.5 \%(21)$ & $12.5 \%(3)$ & 0.08 \\
\hline Concurrent radiotherapy & & $50 \%(1)$ & $50 \%(1)$ & 0.34 \\
\hline Concurrent chemotherapy & & $78.6 \%(11)$ & $21.4 \%(3)$ & 1.00 \\
\hline \multirow[t]{5}{*}{ Primary tumour site } & Alveolar mucosa & $100 \%(11)$ & - & 0.06 \\
\hline & Tongue & $60 \%(3)$ & $40 \%(2)$ & 0.22 \\
\hline & Buccal mucosa & $75 \%(3)$ & $25 \%(1)$ & 1.00 \\
\hline & Parotid gland & $75 \%(3)$ & $25 \%(1)$ & 1.00 \\
\hline & $\begin{array}{l}\text { Other (nasopharyngeal, external auditory canal and } \\
\text { hard palate) }\end{array}$ & $83.3 \%(5)$ & $16.7 \%(1)$ & 1.00 \\
\hline
\end{tabular}

Table 6: Breakdown of the pain characteristics of the study population based on response to the nerve blocks

\begin{tabular}{|c|c|c|c|c|}
\hline \multirow[t]{2}{*}{ Study characteristic } & \multirow[t]{2}{*}{ Category } & \multicolumn{2}{|c|}{ Significant improvement } & \multirow[t]{2}{*}{$P$-value } \\
\hline & & Yes & No & \\
\hline Pain score & Pre-procedure & $6.82 \pm 2.56$ & $7.00 \pm 2.74$ & 1.00 \\
\hline \multirow[t]{2}{*}{ Origin of pain } & Tumour related & $81.8 \%(18)$ & $18.2 \%(4)$ & 1.00 \\
\hline & Tumour and treatment related & $80 \%(4)$ & $20 \%(1)$ & 1.00 \\
\hline Pain laterality & Unilateral & $78.9 \%(15)$ & $21.1 \%(4)$ & 1.00 \\
\hline \multirow[t]{4}{*}{ Distribution of pain } & Ophthalmic division & $100 \%(1)$ & - & 1.00 \\
\hline & Maxillary division & $80 \%(4)$ & $20 \%(1)$ & 1.00 \\
\hline & Mandibular division & $82.4 \%(14)$ & $17.6 \%(3)$ & 1.00 \\
\hline & Cervical nerve (C2-4) distribution & $87.5 \%(14)$ & $12.5 \%(2)$ & 0.37 \\
\hline \multirow[t]{6}{*}{ Quality of pain } & Burning & $87.5 \%(14)$ & $12.5 \%(2)$ & 0.37 \\
\hline & Dull ache & $81.2 \%(13)$ & $18.8 \%(3)$ & 1.00 \\
\hline & Stabbing & $68.8 \%(11)$ & $31.2 \%(5)$ & 0.06 \\
\hline & Throbbing & $100 \%(6)$ & - & 0.56 \\
\hline & Sharp & $50 \%(3)$ & $50 \%(3)$ & 0.06 \\
\hline & Other (electric, shooting) & $75 \%(3)$ & $25 \%(1)$ & 1.00 \\
\hline
\end{tabular}

pain conditions affecting the lower extremities. However, there are no studies, to the best of our knowledge, which evaluate the effectiveness of local nerve blocks in the management of breakthrough pain in HNC-associated neuropathic pain disorders. In the present study, $81.5 \%$ of patients had significant relief in symptoms for nerve blocks. This relief continued beyond 1 month for nearly $60 \%$ of the participants. Similar observations have been reported by investigators who have conducted nerve blocks for the management of primary headache disorders and 
trigeminal neuropathic pain disorders of noncancerous origin. ${ }^{[11,14,15]}$

The mechanism of the prolonged analgesic response of a nerve block longer than the anaesthetic effect is unknown. HNC-associated pain is thought to be generated and sustained by the continuous activation of nociceptors by chemical mediators released by the tumour, such as endothelin-l, nerve growth factor and proteases and protease-activated receptors. ${ }^{[2,3]}$ This continuous activation reduces the threshold of local nociceptors and increases the receptive field of activation (peripheral sensitisation), engages silent nociceptors and increases the excitability of the nociceptive neurons within the nervous system (central sensitisation). ${ }^{[3,19]}$ Given that local anaesthesia blocks regional nociceptors and neurons from carrying any signals to the central nervous system, this reduction in nociceptive traffic may allow wind-down of the peripheral and central sensitisation, which would clinically result in a prolonged analgesic response. ${ }^{[10]}$

In the present study, significant relief in symptoms following a nerve block was statistically associated with the concurrent use of amitriptyline. These findings corroborate the reports from prior studies which have suggested amitriptyline to be effective in the management of neuropathic pain disorders of both oncologic and nononcologic origin. ${ }^{[20-23]}$ While the mechanism of the action of amitriptyline in the management of neuropathic pain is not fully understood, it is known to block the reuptake of serotonin and norepinephrine neurotransmitters, which are involved in the process of pain transmission and pain perception, respectively. ${ }^{[24]}$ Similarly, animalbased investigations on the spinal trigeminal nucleus have suggested that amitriptyline induces segmental inhibition by preventing excessive firing of the wide dynamic neurons, which play a key role in the process of sensitisation. ${ }^{[25]}$ Thus, it appears that amitriptyline synergises the analgesic response of the nerve blocks. Of note, the mechanism of the analgesic response of amitriptyline is likely to differ from the antidepressant action, particularly because analgesic effects of amitriptyline are usually achieved at lower dosages than the onset of any antidepressant effects. Similarly, prior studies have shown that there is no correlation between the effects of tricyclic antidepressants on mood and pain, and tricyclic antidepressants produce analgesia in participants with and without depression. ${ }^{[26]}$

A possible limitation of this study is due to its retrospective nature. Such studies have a low quality in the hierarchy of evidence due to the risk of recall and reporting bias and thus have a strong tendency to form positive association or magnification of the positive responses. Nevertheless, in the present investigation, data were extracted from the electronic hospital information system, which reduced the likelihood of bias. Likewise, patient records from other medical providers were reviewed to corroborate the information that was extracted from the follow-up clinical visits. Furthermore, in this study, we have used stringent criteria for defining a successful outcome to reduce the risk of forming spurious associations. This is the first study that has evaluated the efficacy of using nerve blocks in the management of trigeminal or cervical neuropathic pain associated with HNC. Nonetheless, these results need to be interpreted with caution and necessitate replication. Future trials with a randomised placebo or control study design are advised.

Local anaesthetic blocks, as an adjunctive treatment, can provide significant relief in breakthrough pain in patients with HNC-associated trigeminal and cervical neuropathic pain. However, there is no consistency in how long this relief may last. In addition, the beneficial response of nerve blocks was found to be more common in patients that were concurrently using amitriptyline.

\section{Acknowledgements}

There are no acknowledgements. 


\section{References}

1. Breivik H, Cherny N, Collett B, De Conno F, Filbet M, Foubert AJ, et al. Cancer-related pain: A panEuropean survey of prevalence, treatment, and patient attitudes. Ann Oncol 2009;20:1420-33.

2. Viet CT, Schmidt BL. Biologic mechanisms of oral cancer pain and implications for clinical therapy. J Dent Res 2012;91:447-53.

3. Schmidt BL. The neurobiology of cancer pain. J Oral Maxillofac Surg 2015;73:S132-5.

4. Portenoy RK. Treatment of cancer pain. Lancet 2011;377:2236-47.

5. Fallon MT. Neuropathic pain in cancer. Br J Anaesth 2013;111:105-11.

6. Patin MD. Pain control in head and neck cancer. Curr Opin Otolaryngol Head Neck Surg 1998;86:85-9.

7. Sist T. Head and neck nerve blocks for cancer pain management. Tech Reg Anesth Pain Manag 1997;1:3-10.

8. Yagiela JA. Local anesthetics. Anesth Prog 1991;38:128-41.

9. Malamed SF. Handbook of Local Anesthesia. $5^{\text {th }}$ ed. St. Louis, Mo: Elsevier/Mosby; 2004. p. 399.

10. Levin M. Nerve blocks in the treatment of headache. Neurotherapeutics 2010;7:197-203.

11. Ashkenazi A, Levin M. Greater occipital nerve block for migraine and other headaches: Is it useful? Curr Pain Headache Rep 2007;11:231-5.

12. Naja Z, Naja AS, Rajab O, Mugharbil A, Shatila AR, Al Hassan J. Repetitive nerve block for neuropathic pain management: A case report. Scand J Pain 2018;18:125-7.

13. Thomassen I, Van Suijlekom JA, Van De Gaag A, Ponten JE, Nienhuijs SW. Ultrasound-guided ilioinguinal/iliohypogastric nerve blocks for chronic pain after inguinal hernia repair. Hernia 2013;17:329-32.

14. Perloff MD, Chung JS. Urgent care peripheral nerve blocks for refractory trigeminal neuralgia. Am J Emerg Med 2018;36:2058-60.

15. Lambru G, Abu Bakar N, Stahlhut L, McCulloch S, Miller S, Shanahan $P$, et al. Greater occipital nerve blocks in chronic cluster headache: A prospective open-label study. Eur J Neurol 2014;21:338-43.

16. Olesen J. International classification of headache disorders. Lancet Neurol 2018;17:396-7.

17. International classification of orofacial pain, 1 st edition (ICOP). Cephalalgia 2020;40:129-221.

18. Fallon M, Giusti R, Aielli F, Hoskin P, Rolke R, Sharma M, et al. Management of cancer pain in adult patients: ESMO clinical practice guidelines. Ann Oncol 2018;29:iv166-91.

19. Woolf CJ. Central sensitization: Uncovering the relation between pain and plasticity. Anesthesiology 2007; 106:864-7.

20. Attal N, Cruccu G, Baron R, Haanpää M, Hansson P, Jensen TS, et al. EFNS guidelines on the pharmacological treatment of neuropathic pain: 2010 revision. Eur J Neurol 2010;17:1113-e88.

21. Max MB, Schafer SC, Culnane M, Smoller B, Dubner R, Gracely RH. Amitriptyline, but not lorazepam, relieves postherpetic neuralgia. Neurology 1988;38:1427-32.

22. Mishra S, Bhatnagar S, Goyal GN, Rana SP, Upadhya SP. A comparative efficacy of amitriptyline, gabapentin, and pregabalin in neuropathic cancer pain: A prospective randomized double-blind placebo-controlled study. Am J Hosp Palliat Care 2012;29:177-82.

23. Moore RA, Derry S, Aldington D, Cole P, Wiffen PJ. Amitriptyline for neuropathic pain in adults. Cochrane Database Syst Rev 2015;2015:CD008242.

24. Gillman PK. Tricyclic antidepressant pharmacology and therapeutic drug interactions updated. $\mathrm{Br} \mathrm{J}$ Pharmacol 2007; 151:737-48.

25. Fromm GH, Nakata M, Kondo T. Differential action of amitriptyline on neurons in the trigeminal nucleus. Neurology 1991;41:1932-6.

26. Onghena P, Van Houdenhove B. Antidepressantinduced analgesia in chronic non-malignant pain: $A$ meta-analysis of 39 placebo-controlled studies. Pain 1992;49:205-19.

\section{Authorship Contributions}

Conceived and designed the analysis; $\mathrm{KSN}$ and $\mathrm{HH}$. Collected the data; KSN and AJ. Contributed data or analysis tools; $\mathrm{HH}$ and $\mathrm{RH}$. Performed the analysis; $\mathrm{KSN}$. Wrote the paper; $\mathrm{KSN}, \mathrm{AJ}, \mathrm{HH}$ and $\mathrm{RH}$. 